\title{
O jardim: espelho da vida. Uma leitura de $O$ jardim dos Finzi-Contini
}

Patrizia Collina Bastianetto Universidade Federal de Minas Gerais

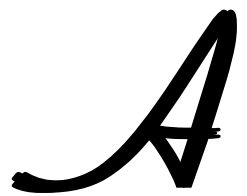

proposta deste estudo é a de refletir sobre o papel do jardim no romance e no filme O jardim dos FinziContini, por meio de uma leitura transemiótica. $\mathrm{O}$ filme, uma produção ítalo-alemã, foi produzido em 1970, sob a direção de Vittorio de Sica. Ele se baseia no romance homônimo do escritor italiano Giorgio Bassani, publicado em 1962. No mesmo ano o livro ganhou o prêmio literário "Viareggio" e o filme, em 1971, ganhou o prêmio "Urso de Ouro", no Festival de Berlim.

O filme, entre outras coisas, mostra a influência do jardim na vida quotidiana das pessoas que dele usufruiam, é portanto, mais do que um simples elemento ornamental da casa onde habitava a família Finzi-Contini, membros da comunidade judaica, da cidade de Ferrara.

Neste trabalho não pretendo tecer comparações pontuais entre o livro e o filme, pois sabemos que são formas de expressões artísticas diversas e autônomas. Gostaria, porém, de ilustrar, tanto no filme quanto no livro, a representação simbólica desse jardim específico, o famoso jardim da família Finzi-Contini. Essa proposta é motivada pelo fato de que, geralmente, o jardim é considerado um apêndice da casa, com função ornamental ou prática. Não acontece isso, porém, no acima referidojardim, que se torna o locus privilegiado do desenrolar da história.
\end{abstract}


Permito-me ilustrar a ligação existente entre o aspecto estético de um jardim e a forma mentis e o modus vivendi da época de sua criação, ou da época que se quer evocar ao criar um determinado jardim. De certa forma, assim acontece também com as traduções. As que se faziam na Europa no período neoclássico são exemplos representativos disso, período em que a estética francesa se sobressaía, e os textos traduzidos precisavam estar em consonância com seu elegante estilo, mesmo resultando numa recriação falha concernente ao aspecto da manutenção de peculiaridades do texto da língua original. Em função disso, as referidas traduções ganharam a fama de serem belles infidèles, isto é, 'belas infiéis', numa analogia com um dito que se costumava usar com relação às mulheres: infiéis se belas e fiéis quando não belas. Após apresentar a ligação existente entre a forma do jardim e a filosofia de sua época, tentarei explorar o valor simbólico do jardim, em algumas obras literárias e, finalmente, na obra e no filme O Jardim dos Finzi-Contini.

\section{A concepção criativa de alguns jardins}

Iniciamos nosso percurso pelos jardins suspensos da Babilônia. Segundo estudiosos do passado, esses foram mandados construir por Nabucodonosor, em homenagem à sua esposa e rainha da antiga Babilônia. O rei criou um jardim cheio de terraços, já que a rainha, apaixonada pelas montanhas de sua terra natal, achava a Babilônia muito plana. Os jardins não eram suspensos, como o nome indica, mas construídos em terraços de tijolos. O tipo de construção os fazia parecer com pequenas elevações, ou montanhas, que poderiam ser vistas de uma distância considerável. Esse fato perpetuou o conceito de jardins suspensos e maravilhosos. De fato, esculturas surgiam dentre piscinas e fontes, a água descia em cascata do largo reservatório sobre a vegetação localizada embaixo. 
Quanto ao jardim japonês, sua forma de ser é geralmente norteada pela filosofia zen, que se baseia em valores como a simplicidade, maturidade, transcendência e serenidade. Para os budistas de zen, o jardim é o ponto ideal para meditação e a contemplação do mundo e da natureza. O jardim japonês costuma ser assimétrico e monocromático, é organizado com contrastes, aproximando aspectos verticais e horizontais, esbeltos e volumosos, estimulando a mente a encontrar seu próprio caminho para a perfeição. Na cultura japonesa o paisagismo é considerado uma forma de arte das mais elevadas, pois consegue expressar a essência da natureza em um espaço limitado.

Já os gregos não possuíam jardins em suas casas, mas apenas em espaços públicos, como nos parques. Eles enfeitavam suas casas com grandes vasos de plantas ou vasos pintados.

Os romanos, ao contrário, construíam jardins grandiosos e magníficos, com uma decoração pomposa, celebrados nos textos antigos, assim como nas pinturas de Pompéia, a antiga cidade do império romano sepultada pelas cinzas, em razão da erupção do vulcão Vesúvio, no ano 79 d.C. Os jardins dos romanos eram conhecidos pela diversidade de sua vegetação, faziam parte integrante da morada, embelezando tanto a casa da cidade, quanto aquela no campo. O jardim era o locus amoenus, ou seja, o lugar ameno de Cicero, valorizado especialmente para fins recreativos.

O jardim da época do Renascimento italiano caracterizavase pela utilização de plantas frutíferas, flores, estátuas e fontes, em um contexto bastante clássico e funcional. Outros elementos também se uniam harmoniosamente ao jardim italiano, como vasos de cerâmica, esculturas, treliças, arcos, pontes, bancos, etc, sempre traduzindo um clima romântico e clássico. Exemplificamos com o Jardim de Boboli, em Florença, um dos primeiros exemplos de jardim italiano, que mais tarde serviria 
de inspiração a quase todas as cortes européias. Nasceu como jardim do Palácio Pitti, residência da família Médici. Desenhado em 1549 por Niccolò Pericoli é hoje um parque histórico da cidade. O visitante caminha por uma alameda de ciprestes que conduz a uma ilha artificial onde estátuas de cavaleiros surgem das águas. Lá fica a Fonte do Oceano, com estátuas dos rios Nilo, Ganges e Eufrates. Destacam-se também o Anfiteatro com a vaca romana e o obelisco egípcio; o Viveiro de Netuno, com a estátua em bronze do deus do mar, e a estátua da Abundância; a Fontana de Bacco e a estátua que representa o anão da corte de Cosimo I, chamado Pietro Barbino, nas vestes de um pescador montado numa tartaruga.

O jardim típico francês, de inspiração italiana, é caracterizado pela perspectiva a perder de vista, como se fosse a continuação da casa, desenhado como um edifício, em uma sucessão de peças. Quem nele andava de carruagem real, ou hoje nele caminha, o faz em um percurso pré-estabelecido. Ele foi construído com princípios de geometria, ótica e perspectiva, revelava ambições estéticas e simbólicas. Os jardins do castelo de Chantilly, por exemplo, são uma das mais notáveis criações de André Le Nôtre (1613-1700), o jardineiro que criou "os jardins à francesa". O parque do castelo cobre 155 hectares, e o jardim já não é mais a continuação do castelo, pois este tornouse acessório do jardim.

Já o jardim inglês é um tipo de jardim desenvolvido durante o século XVIII que, ao contrário dos jardins geométricos nos estilos francês ou italiano, se organiza segundo um conceito de jardim que imita a paisagem natural com rochedos, lagos, riachos, quiosques, dando a sensação de se poder andar por um bosque antigo. Esse modelo irá perdurar até a metade do século XIX, e será exportado para o mundo todo. O jardim inglês é considerado quase um manifesto contra os padrões rígidos e simétricos do estilo francês e italiano. Ele constituirá o cenário ideal para o movimento sócio-cultural do Romantismo. 
$\mathrm{Na}$ atualidade, constatamos que ainda há interesse em pesquisas sobre o mítico jardim do Éden - em hebraico gan Eden-, criado por Deus conforme relatado no capítulo I, do livro do Gênese $(2,8)$, o primeiro livro da Bíblia Sagrada, em que podemos ler: "Ora, o Senhor Deus tinha plantado um jardim no Éden, do lado do oriente, e colocou nele o homem que havia criado" (1997, p. 50). A respeito dessa busca, o jornal americano "The New York Times" informou, segundo o jornal "O Tempo" de 25 de fevereiro de 2011, que cerca de 25 químicos, geólogos, biólogos, físicos e cientistas planetários se reuniram recentemente em Tempe (Arizona), para "ponderar sobre onde teria se localizado o 'Jardim do Éden' e como seria sua aparência". Se para muitos o referido jardim é ficção, para outros é realidade, pois esses últimos entendem que ele seria a marca inicial da história da civilização, onde a humanidade se originou graças à criação do homem adâmico.

Com relação ao significado da palavra Eden, a tradução da Bíblia Sagrada da Editora Vozes (2001, p.25), nas notas de pé de página do capítulo 2, do livro do Gênese $(2,8)$ explica: "Éden em sumério significa 'planície fértil'. Aqui indica uma região ao sul da Mesopotâmia. A ressonância do termo com a palavra hebraica que significa "delícia", e a presente descrição, levaram a entender o jardim em Éden como "jardim de delícias" ou "paraíso" (cf. Is 51,3; Ez 31,9)."

Acreditamos que as informações acima sejam suficientes para que possamos constatar que, mesmo tendo sido alterada ao longo dos séculos a sua concepção, o jardim continua sendo um meio para expressar a filosofia de vida da sociedade de uma determinada época, assim como os sentimentos mais variados do homem, em qualquer momento de sua existência.

E para confirmação disso, nada melhor do que exemplificar com a língua, expressão máxima do ser humano, em que a palavra "jardim", nas mais diversas culturas, é empregada 
pelos poetas e pelos artistas como metáfora do "eu interior". Abrir as portas do jardim e caminhar por ele significa abrir as portas de nossa alma para uma peregrinação interior em busca do auto-conhecimento que leva à felicidade. O jardim é o belo, é a morada da alegria. Com isso concordam os relatos da Criação: tudo o que Deus fez terminou num jardim.

A Septuaginta - tradução do hebraico para o grego, língua geral da antiga Palestina, do chamado Velho Testamento, no século III a.C, feita possivelmente por setenta sábios - traduz a palavra hebraica gan, "jardim", para parádeisos - paradeiso, em grego, cujo significado, em português, é 'paraíso' ou 'parque'. Devido a isso, temos a associação da palavra "paraíso" com o jardim do Éden. Assim como o Paraíso Terrestre de Dante. O escritor florentino o apresenta no Purgatório (XXVIII, 1-2) como a "divina floresta virginal, ampla e sombria" (1979, p. 305). Ela se contrapõe à floresta descrita no Inferno (I, v. 3-6) como uma "selva selvagem, densa e forte, que ao relembrá-la a mente se tortura", em que o peregrino perdido buscava a salvação por estar "longe da boa via, então perdida" (1979, p. 5).

Na floresta infernal reinam o ódio e a raiva, enquanto na floresta divina predomina a harmonia, que simboliza a pacificação do homem consigo mesmo. A natureza se expressa de forma equilibrada, o passar do tempo não leva à velhice, nem traz desilusão ou morte, o ar não sacode as plantas e não machuca os pássaros que podem assim, cantando, expressar sua alegria. O Paraíso terrestre representa o perfeito estado da natureza, em paz consigo mesma, assim como a condição do homem, tendo ele reencontrado a plenitude da vida e seu significado. No Paraíso terrestre reina a primavera perpétua.

Permito-me mais uma pequena digressão: o dicionário de símbolos de Chevalier e Gheerbrant (1962) registra sob a entrada lexical de jardim que esse é "um símbolo do Paraíso Terrestre, do Cosmo de que ele é o centro, do Paraíso celeste, de 
que é representação, dos estados espirituais, que correspondem às vivências paradisíacas".

Como vimos, em geral o jardim está associado ao bem e ao belo, da mesma maneira que ao sentimento mais genuíno de amor e saudade, e dessa forma se apresenta n'Os Lusíadas, Canto VII - 51, de Camões, onde os jardins são "odoríferos e fermosos". Nesse sentido pode ser encontrado também nas canções populares, como, por exemplo, no samba "As rosas não falam", composto por Cartola em 1976 que em um certo trecho diz:

$[\ldots]$

Bate outra vez,

Com esperança o meu coração.

Pois já vai terminando o verão, enfim.

Volto ao jardim,

Com a certeza que devo chorar.

Pois bem sei que não queres voltar,

Para mim.

O jardim com significado de repositório de amor romântico tem exemplo na velha canção francesa do final dos anos cinquenta, Petite fleur:

J'ai caché,

Mieux que partout ailleurs

Au jardin de mon coeur

Une petite fleur.

$[\ldots]$

Dans mon coeur

Tu fleuriras toujours

Au grand jardin d'amour

petite fleur.

[...] 
Também o termo "jardim secreto", remetendo ao ato de cultivar secretamente, dentro de si, os valores espirituais, foi empregado ao longo do tempo por filósofos, artistas, pesquisadores e escritores. É, por exemplo, o título da obra infantil de Frances H. Burnett, publicada em 1909, que inspirou o filme homônimo intitulado "The Secret Garden", produzido em 1993, sob a direção de Agnieszka Hollan.

Acrescente-se o ponto de vista do jardim como local de desenvolvimento emocional e social de crianças, verdadeiras sementes, sob os cuidados de professores e orientadores no papel de "jardineiros": são os Kindergarten, do pedagogo alemão Froebel, os nossos "jardins de infância".

Finalizando esse passeio pelos mais diversos jardins, me permito ainda citar o famoso "Jardim de Epicuro", onde o filósofo grego lecionava no III século a.C. O filósofo entendia que o fim supremo da vida é o prazer sensível - não um prazer imediato, como é desejado pelo homem vulgar -, mas um prazer refletido, filtrado pela razão, escolhido com prudência, sabedoria e filosofia. Para Epicuro a filosofia era um instrumento de libertação e uma via de acesso à verdadeira felicidade. Essa consistiria na serenidade do espírito advinda da consciência de que compete ao homem conseguir o domínio de si mesmo. Contudo, o bem espiritual não seria alcançado unicamente na contemplação, mas também na ação, à maneira grega, na unidade da amizade verdadeira, nas conversas argutas ou, em uma palavra: vivendo ocultamente. E esse ensinamento nos remete fatalmente à obra do escritor e filósofo francês Voltaire, intitulada Candide ou l'optimisme, traduzido para o português como Cândido ou o Otimismo. No último capítulo, por duas vezes, Cândido declara a necessidade de se cultivar seu próprio jardim. A primeira vez, como conclusão às ponderações de Pangloss, seu mestre, acerca do fim trágico de tantos reis e príncipes, todos os homens poderosos. E a segunda vez, falando ainda com Pangloss, ao refutar o otimismo com 
relação à vida que esse queria lhe impingir, tendo em vista que, afinal, após mil desventuras, tudo tinha acabado bem. Voltaire relata que Cândido respondeu "... Cela est bien [...], mais il faut cultiver notre jardin". ${ }^{1}$ Cândido se comportou como um epicurista em busca do bem estar interior alcançado apenas por meio da análise crítica de nosso íntimo, organização e promoção das mudanças necessárias. Para isso, seria preciso, portanto, cultivar "nosso jardim", extirpando as ervas daninhas, adubando e regando, agindo, enfim, como o jardineiro de nós mesmos. A fala de Cândido era também um claro tributo de Voltaire ao Iluminismo que ele abraçara e defendia.

\section{O jardim dos Finzi-Contini na obra de Giorgio Bassani e no filme de Vittorio de Sica}

Observemos agora o jardim da família Finzi-Contini a qual abre, finalmente, as portas para as visitas. É significativo lembrar que isso acontece somente depois que o regime fascista na Itália proíbe aos judeus de freqüentar os locais públicos como, por exemplo, bibliotecas e clubes.

Esta é a estória de Micòl Finzi-Contini, de sua família e dos amigos, apresentada ao público leitor e/ou espectador de forma concomitante com a história mundial nas décadas de trinta e quarenta, do século passado. Os acontecimentos ocorrem quase todos no famoso jardim da família. Assim, o jardim, inicialmente pano de fundo, é incorporado à vida das pessoas, tornando-se locus dos acontecimentos exteriores, espelhando o estado de espírito das personagens. Quando Micòl, por exemplo, está acamada e triste, chove, e o jardim está encoberto por uma neblina densa.

${ }^{1}$ VOLTAIRE, 1959, p. 224. 
No prólogo ao livro, seu autor, Giorgio Bassani, explicita a gênese da obra e conta que uma sua visita à necrópole etrusca de Cerveteri (1957) o levou a refletir sobre a relação dialética existente entre a vida e a morte, relação fortemente ligada ao passado e ao presente. Naquela oportunidade, recordou a sua cidade de Ferrara e o cemitério judaico, lembrando especialmente o túmulo monumental da família Finzi-Contini onde jazia apenas um membro daquela família. Era Alberto, com quem Bassani havia convivido durante os anos anteriores à Segunda Guerra Mundial. Esse livro quis ser uma homenagem póstuma àquele grupo de judeus da cidade de Ferrara, que morreram nos Lager nazistas e que renasceriam apenas por meio da literatura.

O acontecimento é ambientado, portanto, no período da implantação, na Itália, das leis raciais, editadas em 1938, uma versão italiana das Leis de Nüremberg, que a Alemanha nacionalsocialista havia promulgado três anos antes, em 1935. Essas leis, no começo, diferentemente das do aliado germânico, não foram muito sentidas, pois, o espírito um tanto anárquico italiano ou o hábito de não observar as leis à letra, meio "laissez faire, laissez passer", como diriam os franceses, fez com que as diversas proibições restritivas demorassem a ser implementadas. Contudo, com o início da radicalização decorrente do início da guerra, bem como com o alinhamento mais intenso com a Alemanha antisemita, elas passaram a vigorar de fato, e muitas famílias foram atingidas e deportadas. Nesse contexto, os judeus haviam sido proibidos de contrair casamento com pessoas de outra religião, seus nomes não podiam constar nos obituários dos jornais, não podiam ter serviçais e, mais tarde, foram impedidos de possuir imóveis. Os jovens foram proibidos de frequentar a escola pública, a biblioteca e foram excluídos, também, de todas as associações culturais e recreativas. Era a verdadeira morte social.

A escritora italiana Rosetta Loy, em La parola ebreo, relata o absurdo dessa morte social, quando o sistema fez recair sobre 
os judeus italianos, perfeitamente integrados na sociedade italiana há muito, o rótulo de "os outros" ou, numa expressão alemã típica, os Fremdkörper, ou seja, os corpos estranhos. Os agentes da polícia alemã, então absolutos na Itália fascista, iam buscá-los, para levá-los aos campos de trabalho ou de morte. Assim diz Loy:

Per troppo tempo avevano condiviso con noi giornate tristi e felici, paure, viltà, speranze. Erano saliti e scesi per le medesime scale, avevano bevuto lo stesso tè e girato il cucchiaino nella tazza parlando la medesima lingua: in senso lessicale, ma anche nel senso dei sentimenti. Troppo tempo, per sentirsi altri. Come immaginare quella mostruosa solitudine davanti alle SS, a quegli ordini che senza inflessione nella voce, nello spazio di venti minuti, li cancellavano dall' Humano genere? ${ }^{2}$

Nesse contexto, a família Finzi-Contini abriu as portas de seu jardim para que lá fosse realizado o torneio anual de tênis. Os jovens tenistas eram belos e ricos, estavam otimistas, certos de que haveria uma rápida resolução dos conflitos políticos, pois seria apenas uma questão de tempo, para que tudo se resolvesse de forma pacífica. Esse otimismo é típico da juventude, mas nesse caso se originava, em parte, da história dos judeus na Itália, onde, até então, não haviam sofrido as perseguições a que foram submetidos em outros países.

${ }^{2}$ Por muito tempo tinham compartilhado conosco dias tristes e alegres, medo, covardia, esperança. Tinham subido e descido a mesma escada, tomado o mesmo chá, mexido a colherinha na xícara falando a mesma língua com relação às palavras e aos sentimentos. Tempo demais para se sentirem os outros. Como imaginar aquela solidão monstruosa na presença dos soldados da SS e suas ordens sem inflexão alguma, como acreditar que em vinte minutos eles eram cancelados do Humano genere? (LOY, 2002, p.135-136). Tradução nossa. 
A história de Ferrara registra a presença de judeus desde o ano de 1227. Os arquivos documentam que no ano de 1310 viviam na cidade dezessete famílias de judeus. Nos séculos XV e XVI, sob a administração das famílias Estensi e depois da família d'Este, no regime da signoria, Ferrara acolheu judeus sefarditas, de origem espanhola e portuguesa, oriundos da Península Ibérica (1492 e 1532). A cidade acolheu também os judeus ashkenazitas, provenientes da Europa central, especialmente alemães, austríacos e poloneses. Demograficamente, sua presença tornou-se assim bastante significativa; dos 30.000 habitantes de Ferrara, 2.000 eram judeus. Sua condição econômica era bastante favorável, os estatutos da cidade autorizavam, pois, o exercício de muitas atividades profissionais e comerciais, e não somente o do empréstimo a juros, como acontecia em muitas outras cidades da península. A cidade reuniu cidadãos de diversas culturas que, além de conviverem pacificamente, enriqueceram-na em termos culturais e sociais.

Em 1534, quando Alfonso d'Este morreu, sem deixar herdeiros homens, a cidade de Ferrara foi anexada ao Papado e o Duca Cesare d'Este transferiu sua corte para a cidade de Modena. Muitos judeus o acompanharam e aqueles que ficaram tiveram negados, progressivamente, alguns de seus direitos. A liberdade foi perdida e foram destinadas a eles, para habitação, áreas ou bairros específicos, chamados de guetos, tendo o de Ferrara sido instituído em 1627. Os guetos, contudo, foram extintos em 1860 com a unificação da Itália, quando os judeus passaram a ser cidadãos com todos os direitos civis garantidos como os dos italianos. Os judeus de Ferrara estavam completamente integrados à cidade, seus negócios floresciam e prosperavam.

Com o mesmo otimismo com que os jovens acreditavam que a resolução dos problemas políticos estaria em um acordo diplomático, dependendo apenas de tempo, Giorgio Bassani, 
o protagonista narrador, acreditava que a conquista de Micòl, a quem ele amava desde criança, também fosse apenas uma questão de tempo. Entretanto, na medida em que a crua realidade histórica se impunha, aumentava também a incompreensão entre os dois jovens, o mundo idealizado do jardim desabava, culminando no trágico desfecho da protagonista, de sua família e de muitos outros judeus. Nesse momento não se tratava mais apenas da morte social, mas da cruel realidade histórica, que levaria grande parte deles à morte física.

Enquanto a magna domus, isto é, a casa grande, estava inerte, no jardim a vida pulsava. Era nele que se refugiaram e se divertiam Micòl, seu irmão Alberto e os amigos. Ao todo eram dez, como os jovens personagens de Boccaccio do Decameron que, em 1348, fugiram da peste que assolou 4/5 da população de Florença, em busca da salvação no paraíso idealizado de sua casa de campo.

Os jovens de Ferrara jogavam tênis nas mágicas tardes de primavera e de verão escaldante entre os anos de 1938 e 1943, viviam ingenuamente felizes naquela natureza pródiga e exuberante. Mas, assim como o jardim, também eles sofreram no gélido inverno, até a partida para a viagem fatal. $\mathrm{O}$ idealismo, a inconsciência da idade "em flor" acabaria abruptamente.

O interior da magna domus é descrito muito vagamente, apenas o quarto de Micòl é apresentado com detalhes e clareza ao leitor. Já o jardim, como veremos a seguir, é descrito muitas vezes em páginas seguidas do livro, é alçado a personagem, que reage aos estímulos externos, sejam eles positivos ou negativos. Ele adquire um valor simbólico, está em sintonia profunda com os fatos da vida, eis porque o chamei de "espelho da vida". Para exemplificar, cito a seguir apenas alguns trechos do livro, seguidos do número da página. 
"Tendo o jardim uns dez hectares, e as alamedas, umas maiores outras menores, somando todas juntas, cerca de doze quilômetros." (p. 78)

"Estávamos [...] em meio a moitas de filifolhas, urtigas e abrolhos espinhosos, quando de repente, detrás da espessa barreira de troncos..." (p. 78)

[...] "o jardim ou, para sermos mais exatos, o parque interminável que circundava a casa Finzi-Contini antes da guerra e que se expandia por quase dez hectares [...] constituindo algo de raro, de excepcional (os guia do Touring do início do século jamais deixavam de mencionálo ....)". (p. 13-14)

"Todas as árvores de tronco grosso: tílias, olmos, faias, álamos, plátanos, hipocastaneáceos, pinhos, abetos, lariços, cedros-do-líbano, ciprestes, carvalhos, azinheiras, até palmas e eucaliptos, plantados às centenas..." (p. 14).

"Podia referir-se a honestos olmos e tílias nacionais ou a raríssimas plantas africanas, asiáticas, americanas [...] havia de tudo em Barchetto del Duca, tudo mesmo." (p. 79)

"Micòl considerava Alberto quase um "monstro" por não saber identificar as árvores pelo nome e lhe parecia um absurdo que pudesse existir "uma pessoa como eu [Alberto] no mundo, que não nutria pelas árvores, "... as grandes, as plácidas, as fortes, as meditativas...", os mesmos sentimentos de apaixonada admiração. Como eu podia não entender, meu Deus, não sentir?" (p. 79)

"No fundo da clareira do tênis havia, por exemplo, [...] um grupo de sete frágeis altíssimas Washingtoniae graciles, ou palmas-do-deserto, separadas do resto da vegetação posterior [...] Micòl sempre dirigia para as Washingtoniae novas palavras de ternura. - Eis os meus sete velhinhos com barbas veneráveis! - dizia às vezes -. - Olha que barbas veneráveis eles têm!" (p. 79) 
"Quanta elegância, quanta santidade nos seus troncos escuros, secos, curvos, enrugados!" (p. 79)

"Em relação a um enorme plátano, de tronco esbranquiçado e nodoso, maior do que qualquer outra árvore do jardim e, creio, de toda a província, sua admiração alcançava os limites da reverência. Naturalmente [...] quem o plantara fora Ercole I d'Este em pessoa, ou talvez a própria Lucrecia Borgia. - Tem quase quinhentos anos, entende? [...] - Pense só quantas coisas deve ter visto, desde quando veio ao mundo. E parecia que o plátano gigantesco tivesse de fato olhos e ouvidos: olhos para nos ver e ouvidos para nos escutar." (p. 79-80)

"Já as plantas frutíferas inspiravam apenas carinho, eram humildes plantas domésticas, a serviço do homem, cujos frutos eram nomeados apenas no dialeto, a língua do aconchego do lar, falada pelo mordomo". (p. 80)

"Chegando o inverno, Micòl via através dos vidros, os "cimos barbudos das suas Washingtoniae graciles que a chuva e o vento batiam "indignamente" (p.92), cujos troncos já estavam sendo agasalhados pelos empregados, como todos os invernos, com cada retorno da má estação".

"Giorgio, depois de roubar um beijo a Micòl, ela se enfurece e o afasta de seu convívio, ele sofre, mas obedece na vaga esperança de um dia poder voltar a juntar-se a ela e aos lugares "paradisíacos" dos quais tinha sido excluído". (p. 182)

Com relação ao jardim apresentado no filme, seguem também algumas observações. O título do filme, tanto em inglês como em português, mantém a palavra "jardim", traduzida literalmente do título do livro em italiano. Essa observação não é tão banal como poderia parecer, pois sabemos que não é praxe traduzir de forma literal o título de uma obra literária, no caso de uma adaptação para o cinema. Nesses 
casos, o título do filme costuma ser escolhido de forma a evocar aspectos interessantes, que cativem o público espectador específico da cultura para a qual a obra é traduzida. Dessa forma, a manutenção da palavra "jardim", tanto na tradução do livro quanto na produção fílmica para o português e o inglês atesta a relevância do jardim na obra em questão.

Sabemos, também, que o recurso mais expressivo do cinema não é o texto, mas são o som e a imagem. No filme, o diretor soube explorá-los com a grande maestria que o caracterizava, nesse caso, com a força e a delicadeza necessárias.

$\mathrm{Na}$ apresentação dos créditos do filme há cenas que remetem às quatro estações do ano, como são também as estações da vida do ser humano. Nas primeiras cenas aparece um parque com árvores multicoloridas e imponentes, os pássaros voando em liberdade. As tomadas são lentas, o olhar do espectador pousa em uma alameda larga e arborizada que, de repente, é tomada pela algazarra de jovens chegando alegremente ao campo de tênis. Durante os passeios de Micòl e Alberto pelo parque, as árvores dominam de forma imponente e são também protagonistas, muitas vezes alçadas a tema das longas conversas.

A estrutura narrativa é sustentada por uma trilha sonora que interpreta e ilustra o estado de espírito das personagens. Nos tempos de felicidade toca a música Vivere, isto é, 'Viver', de autoria de C. A. Bixio. Essa música é um hino à vida, composta, por coincidência ou não, em 1938, ano da implementação, na Itália, das leis raciais. Já, para Micòl, protagonista e personagem emblemática, é especialmente composta uma trilha sonora intitulada "Micol's theme".

Já a saída da magna domus da família Finzi-Contini é acompanhada por um fundo musical triste e desesperado, repleto de pathos. Enquanto Shalom Katz interpreta de forma suplicante o canto judeu "El Mole Rachamim" (Senhor Misericórdia), o carro 
preto da polícia fascista desliza na larga alameda gelada. As grandes árvores cobertas de neve estão inertes, assim como Micòl e seus pais, o professor Ermanno e a senhora Olga. Sua expressão marmórea indica a submissão ao destino que parece ser inelutável. Pela janela do carro, o espectador avista os tetos de Ferrara se afastando lentamente e aparecem alguns flash back dos tempos de felicidade. E sempre ao som suplicante do canto judeu, por meio de um lento zoom se aproxima da vista do espectador a maior árvore do jardim dos Finzi-Contini. Ela não está mais envolta na protetora camisa de palha, mas "indignamente" exposta às intempéries, espelhando a vida real. E devagar desvanece atrás da neve que tudo encobre. $\mathrm{O}$ triste canto, verdadeiramente fúnebre, simboliza a despedida derradeira: para eles, as próximas horas serão o princípio do fim, a casa, o jardim e a vida perdidos para sempre.

$\mathrm{O}$ jardim, esse mundo de refúgio, ilusão, beleza, romantismo, paz e poder, sempre esteve presente na existência humana, em todos os quadrantes do mundo, desde a Antiguidade. Construí-lo significava acrescentar à vida algo de nobre, de delicado, de superior. Real ou plebeu, privado ou público, imponente ou discreto, requintado ou modesto, coberto de flores e de verde, ou simplesmente submerso na neve, tem sido repositório de alegria, de paz ou de solidão e abandono. O jardim da magna domus dos Finzi-Contini, antes povoado pelo esplendor e otimismo da juventude que o freqüentava, havia ficado para trás, na vida daquela família e de seus freqüentadores. Como outros judeus de Ferrara, partiram, possivelmente, com a certeza de que não retornariam jamais; mas, diferentemente deles, tinham outra certeza, a de que o seu outrora belo jardim somente restaria vivo em sua memória, enquanto a morte não chegasse. 


\section{Referências bibliográficas}

DANTE ALIGHIERI. A Divina Comédia. São Paulo: Ed. Itatiaia, 1979. 2. ed. Trad. Cristiano Martins. V. 1 e V. 2.

BASSANI. G. Il giardino dei Finzi-Contini. Milano: Oscar Mondadori, 1976.

BASSANI. O jardim dos Finzi-Contini. Rio de Janeiro: Rio Gráfica, 1987.

BERTHOLET, F.; REBER, K. Jardins antiques. Grèce - Gaule - Rome. Regards sur l'antiquité. Gollion, CH: Infolio Éditions, 2010.

BÍBLIA SAGRADA. 107. ed. Edição Claretiana. Tradução dos originais pelo Centro Bíblico Católico. São Paulo: Editora Ave Maria, 1997.

BÍBLIA SAGRADA. Petrópolis: Editora Vozes, 2001.

CAMÕES, L. de. Os Lusíadas. 2. ed. Porto: Porto Editora, s.d.

CHEVALIER, J.; GHEERBRANT, A. Dicionário de símbolos. 18. ed. Rio de Janeiro: José Olimpio Editora, 1906.

DE CRESCENZO. L. Storia della filosofia greca - da Socrate in poi. Milano: Arnoldo Mondadori Editore, 1986.

LOY, R. La parola ebreo. 2. ed. Torino: Einaudi Editore, 2002.

ROMAGNA, Regione Emilia. Luoghi ebraici in Emilia Romagna. Milano: Touring Club Italiano, 2003.

VOLTAIRE. Candide ou l'optimisme. Paris: Nizet Éditeur, 1959.

O TEMPO. Belo Horizonte - Ano 15 - Caderno Interessa, 25 fev. 2011, p. 17. 


\section{Resumo}

Este artigo tem como objetivo fazer uma leitura, a partir de uma abordagem semiótica, do romance $O$ jardim dos Finzi-Contini, de 1962, do escritor italiano Giorgio Bassani, e do filme homônimo produzido em 1970, sob a direção de Vittorio de Sica. Pretende, ainda, ilustrar o valor simbólico do jardim nessa obra e apresentar a concepção criativa de alguns jardins famosos.

\section{Résumé}

Cet article présente une lecture sémiotique du roman $O$ jardim dos Finzi-Contini, de l'écrivain italian Giorgio Bassani, publié en 1962, et du film homonyme du réalisateur Vittorio de Sica, paru en 1970. On essaye aussi d'y vérifier la valeur symbolique du jardin et de présenter la conception créative de quelques jardins connus. 